\title{
NUMERICAL AND PHYSICAL SIMULATION OF STEEL LADLE DRAINING OPERATION WITH DIFFERENT WELL BLOCK DESIGN
}

\author{
Paulo Vinícius Souza da Conceição ${ }^{1,2}$ \\ Carlos Antônio da Silva ${ }^{3}$ \\ Itavahn Alves da Silva ${ }^{3}$ \\ João Victor Gomes Guimarães Ananias ' \\ Alexandre Dolabella Resende ${ }^{4}$
}

\begin{abstract}
At the end of a ladle draining operation a structure called drain sink forms at the top surface of the liquid steel allowing slag carry over from the ladle to the tundish and causing metallic losses. On this study, the effect of different well block configuration on the critical height for drain sink formation $\left(\mathrm{H}_{\mathrm{C}}\right)$ was investigated using numerical and physical modeling. The modified well block configuration showed lower $\mathrm{H}_{\mathrm{C}}$ in most of the cases when compared with the standard design. It could represent almost $50 \%$ of metallic lost savings during the continuous casting process. Air injection was also investigated and increased significantly the $\mathrm{H}_{\mathrm{c}}$ value. The numerical model showed good agreement with the physical model and was used to help undertanding this behavior.
\end{abstract}

Keywords: Drain sink; Well block; Metallic yield; Gas injection.

\section{INTRODUCTION}

A number of studies [I-3] shows that by the end of a ladle draining operation a structure called vortex or drain sink forms at the top surface of the liquid steel allowing slag carry over from the ladle to the tundish. This happens because, as the liquid steel level becomes low enough, the steel flow towards the nozzle bore is smaller than the actual steel flow through the nozzle bore causing a flow imbalance and surface collapse. The result is slag entrainment. Emulsificated slag in the liquid steel will likely be carried to the mold and cause steel quality issues as surface defects. Depending on the slag reoxidation of $[\mathrm{Al}]$, $[\mathrm{Si}]$ and $[\mathrm{Mn}]$ can take place in the tundish causing steel down grading. Not less important depending on the amount of slag added heat by heat into the tundish the refractory lining will suffer a significant wear caused by chemical corrosion that could cause an early tundish fly or even the end of the casting sequence.

Steelmakers employ a number of devices to minimize slag carry over from ladle to tundish such as slag detector systems [4] but the most common systems still remain human dependent and will only detect the slag after it comes to the tundish and floats to the surface. Zhang [5] have proposed to detect the onset of second phase suction by analyzing the vibration pattern as compared with a single phase flow.

Few artifices are employed in some steel shops in order to increase the metallic yield. The most common it is to brick the well block lower than the remaining of the ladle bottom [6]. This will not affect the drain sink formation height but as the bottom is in an upper position less steel will remain in the ladle before slag entrapment. However as the refractory wears out the whole bottom becomes flat again and this kind of construction will lose effect. Also, depending on the bottom construction (impact pads, well block and plug block positions) it could be very hard or more expensive to brick such solution. Thus it would be beneficial to develop a tailor made device that minimizes the steel left over when vortex starts to form. It is worth mentioning that every $\mathrm{Icm}$ height in a $4 \mathrm{~m}$ diameter ladle retains almost I ton of steel. Postponing the start of vortex/drain sink formation will allow steelmakers to cast more steel without compromising steel quality.

Studies have been conducted in order to explain and predict the funnel formation [7] and it is quite known that two different mechanisms can lead to the collapse of the top surface of a draining liquid: vortex sink or drain sink. Vortex sink it is a phenomenon described by few authors as a funnel formed when a high tangential speed at the vicinity of the nozzle bore is present. Mazzaferro [8] has studied the influence of the well block location on the drainage of cylindrical ladles tangentially filled. They found out that as the block moves towards the ladle wall less vortex sink is observed. Taking into account the industrial practices they conclude that no vortex sink should be observed on draining ladles.

'Universidade Federal de Ouro Preto - UFOP, Contagem, MG, Brasil.E-mail: paulo.souza@rhimagnesita.com

${ }^{2}$ RHI Magnesita, Contagem, MG, Brasil.

${ }^{3}$ Escola de Minas de Ouro Preto, Universidade Federal de Ouro Preto - UFOP, Ouro Preto, MG, Brasil.

${ }^{4}$ Departamento de Simulação Numérica e Soluções, RHI Magnesita, Contagem, MG, Brasil.

2176-1523 @ 2019 Associação Brasileira de Metalurgia, Materiais e Mineração. Published by ABM. This is an open access paper, published under the Creative Commons CC BY-NC-ND license (Attribution-NonCommercial-NoDerivs) - https://creativecommons.org/licenses/ by-nc-nd/4.0/. 
At the late drainage stage when the radial liquid flow towards the nozzle bore is smaller than the maximum flow allowed by the nozzle the top surface of the liquid collapses forming the drain sink. Its formation does not depend on a previous vortex existence. Drain sink is reported to be the main source of ladle to tundish slag carryover [8] and as such is widely discussed for either explaining and predicting its appearance or developing a way to reduce its formation height $\left(\mathrm{H}_{\mathrm{C}}\right)$.

The drain sink formation height was reported to be of the same order of magnitude of the nozzle bore size [9]. The $\mathrm{H}_{c}$ was found not to be dependent on nozzle position, vessel diameter and the shape of vessel $[8,9]$. Hammerschmid et al. [ 1 ] stated that the larger the resting time before draining start the smaller the $\mathrm{H}_{\mathrm{C}}$. They also have found that gas injection on the bottom of the ladle decreases $\mathrm{H}_{\mathrm{C}}$. The same was observed by other authors [10] after injection of gas at the four corners of the well block during the ladle draining. In a previous study [6] $\mathrm{H}_{\mathrm{C}}$ has reduced by introducing physical obstacles to postpone drain sink formation. Also in the same study was reported that the larger the flow rate the larger the $\mathrm{H}_{\mathrm{C}}$. Morales and Davila [ I I] have developed a mathematical model considering thermal losses and its influence at the flow pattern and the drain sink formation. Li et al. [12] have performed mathematical simulations using Fluent (Ansys) after model calibration provided by physical modeling. Their work stress the importance of the flow pattern at the ladle bottom as far as drain sink formation process is concerned.

Isothermal physical modeling has been used to investigate drain sink formation with two different well block designs and with/without air injection. Numerical modeling was made to mimic the physical trials and also to become a new tool, faster and cheaper, to develop a new costumer made well block enhanced yield design. Air injection was introduced in order to reduce $\mathrm{H}_{\mathrm{c}}$.

\section{METHODOLOGY}

A cylindrical model following a 1:6.5 scale of an industrial ladle was made of acrylic, with inner diameter of $380 \mathrm{~mm}$ and $690 \mathrm{~mm}$ height. Since draining a ladle is gravity dominated the Froude number, $\mathrm{Fr}=\mathrm{V}^{2} / \mathrm{Lg}$, has been used as a primary similarity criterion. A changeable bottom plate allowed to positioning two different well block geometries (Figure I). Both designs have the same height and the same bore size. Also all the piping underneath the bottom part of the well block were kept constant for comparison purposes. A circular porous element assembled at the top of the modified well block was used for air injection during the draining process. Inside the block a photoelectric sensor as well as a light source have been placed in order to detect the passage of the fluids.

A continuous capture of the electric magnetic field (e.m.f) signal generated by the light impinging on photoelectrical sensor is made by a data collector. During the experiments the light going through the crystalline water gives a certain value of e.m.f. When drain sinks occurs the air funnel formed inside the well block disturbs the light passage and a different value of e.m.f emerges. The draining process is interrupted at the onset of this change, the remaining water is collected and weighted and the $\mathrm{H}_{C}$ is then estimated. Each experiment was done $10 \mathrm{x}$ and the lowest and highest values were not considered. The Table I shows the experimental conditions. The liquid flow rate was kept constant during each experiment.

Figure 2 shows on the left the sliding gate refractories set and on the right the modified well block 3D printed with a refractory porous ring. The draining was performed with no air injection, $21 / \mathrm{min}$ and $51 / \mathrm{min}$ and stalled at predetermined liquid levels. All the other variables were kept constant.

Table I. Experimental conditions

\begin{tabular}{lcc}
\hline \multirow{2}{*}{ Well Block } & \multicolumn{2}{c}{ Physical Model } \\
\cline { 2 - 3 } & Standard & Modified \\
\hline Filling & $* \mathrm{~T} / * * V$ & $\mathrm{~T} / \mathrm{V}$ \\
Height $(\mathrm{cm})$ & 10 and 20 & 10 and 20 \\
Resting Time $(\mathrm{min})$ & 0 and 10 & 0 and 10 \\
Liquid Flow Rate $(\mathrm{I} / \mathrm{min})$ & $5,7,9$ & $5,7,9$ \\
Air Injection $(\mathrm{I} / \mathrm{min})$ & $\mathrm{No}$ & 2,5 \\
\hline
\end{tabular}

*Tangential; **Vertical.

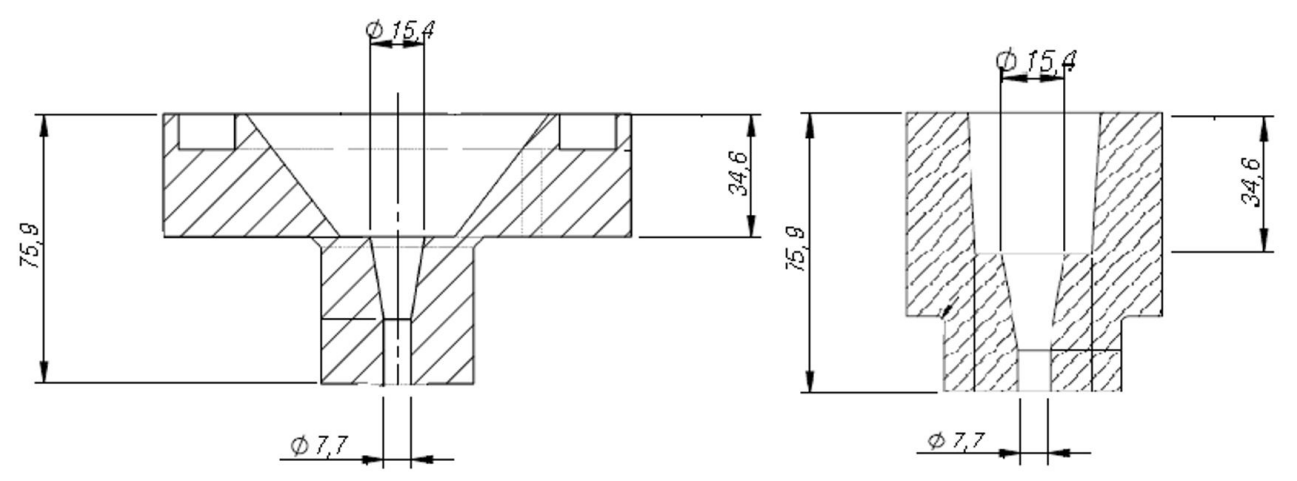

Figure I. On the left: standard well block design and on the right: new well block design. 


\section{I Numerical Simulation}

Mathematical modeling was performed using Ansys CFX $[13,14]$. Turbulence was modeled through the k-epsilon model. Therefore, the fluid flow equations which govern the phenomena for isothermal flow conditions are:

$$
\begin{aligned}
& \frac{\partial \rho}{\partial t}+\frac{\partial}{\partial x_{j}}\left(\rho U_{j}\right)=0 \\
& \frac{\partial \rho U_{i}}{\partial t}+\frac{\partial}{\partial x_{j}}\left(\rho U_{i} U_{j}\right)=-\frac{\partial P}{\partial x_{i}}+\frac{\partial}{\partial x_{j}}\left[\mu_{\text {eff }}\left(\frac{\partial U_{i}}{\partial x_{j}}+\frac{\partial U_{j}}{\partial x_{i}}\right)\right]+S_{M}
\end{aligned}
$$

Where $S_{M}$ is the sum of the body forces and $\mu_{\text {eff }}$ is the effective viscosity accounting for turbulence, given by:

$$
\mu_{e f f}=\mu+C_{\mu} \rho \frac{k^{2}}{\varepsilon}
$$

Where $\mathrm{C}_{\mu}$ is a constant.

Equations 4 and 5 represent the transport equations for turbulent kinetic energy $(k)$ and dissipation rate of turbulence $(\varepsilon)$ :

$$
\begin{aligned}
& \frac{\partial \rho k}{\partial t}+\frac{\partial}{\partial x_{j}}\left(\rho U_{j} k\right)=\frac{\partial}{\partial x_{j}}\left[\left(\mu+\frac{\mu_{t}}{\sigma_{k}}\right) \frac{\partial k}{\partial x_{j}}\right]+P_{k}-\rho \varepsilon \\
& \frac{\partial \rho \varepsilon}{\partial t}+\frac{\partial}{\partial x_{j}}\left(\rho U_{i} \varepsilon\right)=\frac{\partial}{\partial x_{j}}\left[\left(\mu+\frac{\mu_{t}}{\sigma_{\varepsilon}}\right) \frac{\partial \varepsilon}{\partial x_{j}}\right]+\frac{\varepsilon}{k}\left(C_{\varepsilon 1} P_{k}-C_{\varepsilon 2} \rho \varepsilon\right)
\end{aligned}
$$

Where: $\sigma_{\mathrm{k}}=$ Prandtl number for turbulent kinetic energy, $\sigma_{\varepsilon}=$ Prandtl number for dissipation rate of turbulent kinetic energy.

The equations above were solved for a homogeneous multiphase flow field, as the position of the free surface between the fluids at the moment of air aspiration is the main objective of the model. To properly describe the multiphase flow field, Equations 3-7 must be solved for the bulk flow, assuming all fluids share a common flow field $[1 \mathrm{I}, 12]$. For the calculation of the bulk flow, the density and viscosity values from Equations I-5 must be replaced by the equivalent mixture quantities, given by:

$$
\rho=r_{\text {air }} \rho_{\text {air }}+r_{\text {water }} \rho_{\text {water }}
$$

$$
\mu=r_{\text {air }} \mu_{\text {air }}+r_{\text {water }} \mu_{\text {water }}
$$

Where $r$ is the volume fraction of a given phase at each cell. For a two-phase model consisting of air and water, we can consider the following (Equation 8):

$$
r_{\text {air }}+\boldsymbol{r}_{\text {water }}=1
$$

The mathematical simulations were performed in a I:6.5 scale isothermal water model. The $\mathrm{H}_{\mathrm{c}}$ value has been evaluated taking in consideration the elapsed time when a significant drop on the mass flow rate takes place, which can be related to a second phase (gas) being sucked into the nozzle bore. The boundary condition at the outlet is the velocity calculated to match the volumetric flow rate of the experiments, which did not vary significantly during the teeming process. As the outlet has a prescribed velocity, any change in the density of the incoming fluid will be detected as a variation of the mass flow through the nozzle. Table 2 shows the fluids properties for this simulation.

The top surface was regarded as an opening at the atmospheric pressure, to allow air to enter the domain as the water level gets lower. No-slip boundary conditions were applied at the ladle walls.

\section{RESULTS AND DISCUSSION}

The relationship between the water flow rate and $\mathrm{H}_{\mathrm{C}}$ was studied and as it can be seen on Figure 3 on the left and in accordance with the literature the larger the water flow rate the larger is the $\mathrm{H}_{C}$ value. This can be noticed in all 4 situations (standard and modified well block - vertical and tangential filling). Comparison involving different filling patterns shows a higher $\mathrm{H}_{\mathrm{C}}$ value with tangential filling, what is in agreement with previous work [5].

Table 2. Fluid Properties for the draining simulations

\begin{tabular}{lcc}
\hline \multicolumn{1}{c}{ Property } & Water & Air \\
\hline Density $\left[\mathrm{kg} / \mathrm{m}^{3}\right]$ & 997 & 1.185 \\
Dynamic Viscosity $[\mathrm{Pa} . \mathrm{s}]$ & $8.89 \times 10^{-4}$ & $1.83 \mathrm{I} \times 10^{-5}$ \\
\hline
\end{tabular}

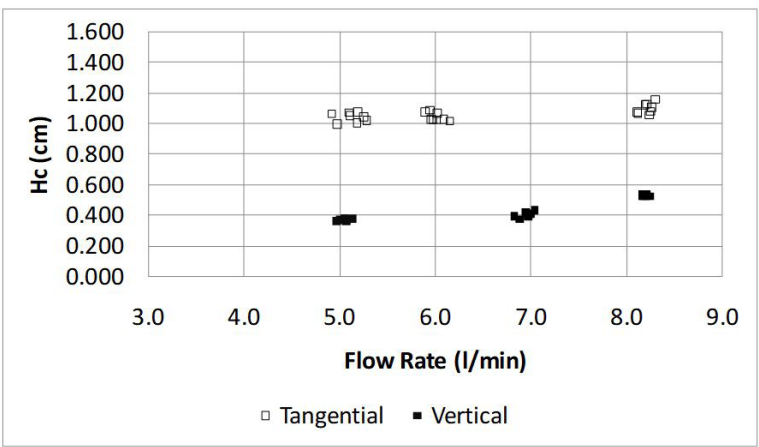

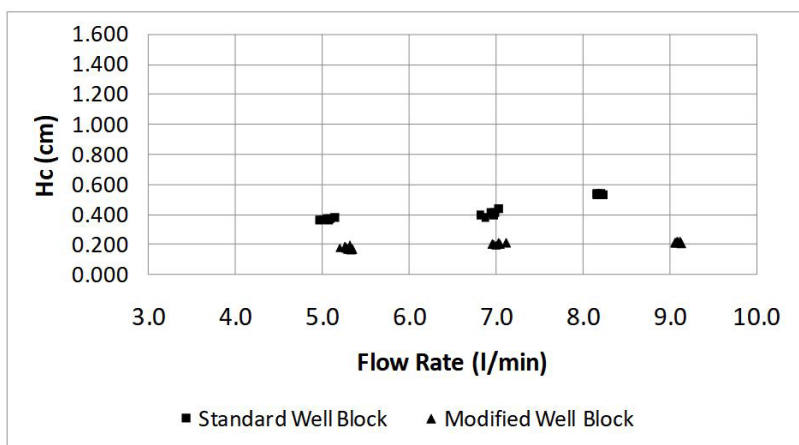

Figure 2. Left: Sliding gate refractory set. Right: Photo of the modified well block 3D printed assembled with refractory porous ring. 
Comparison of different well block designs suggests (Figure 3 - on the right) that the new design was able to remarkably reduce the $\mathrm{H}_{\mathrm{c}}$ for all flow rates. Also the difference between them increases when the flow rate increases. This is because for the new design $\mathrm{H}_{C}$ is much less affected by the flow rate compared with the standard one.

Statistical analyses were carried out comparing both designs (Table 3). First the F-Test was used to evaluate if the $\mathrm{H}_{0}$ hypothesis that both population have equal variance is true. This hypothesis was not rejected because $F>P(F<=f)$ for the case of one tailed test. For all three flow rates the results were the same.

By knowing that the two populations had equal variance a second test was performed but now comparing the two means: the T-Test for mean for populations with same variance. For all three flow rates the hypothesis of equal mean $\left(\mathrm{H}_{0}\right)$ was rejected because Stat $t>t$ critic two tailed. Therefore there a statistical proof that the modified well block presents lower results in terms of $\mathrm{H}_{\mathrm{C}}$.

Air injection did not decrease the $\mathrm{H}_{c}$; quite the contrary air injection did increase significantly its value in almost I0x despite what few authors say [5,9]. It was not observed a correlation between the air flow rate and the $\mathrm{H}_{\mathrm{C}}$ value. The Figure 4 shows the results and a photo of the experiments. Air bubbles where homogeneously distributed throughout the porous ring. No air entrapment was observed during the ladle draining.
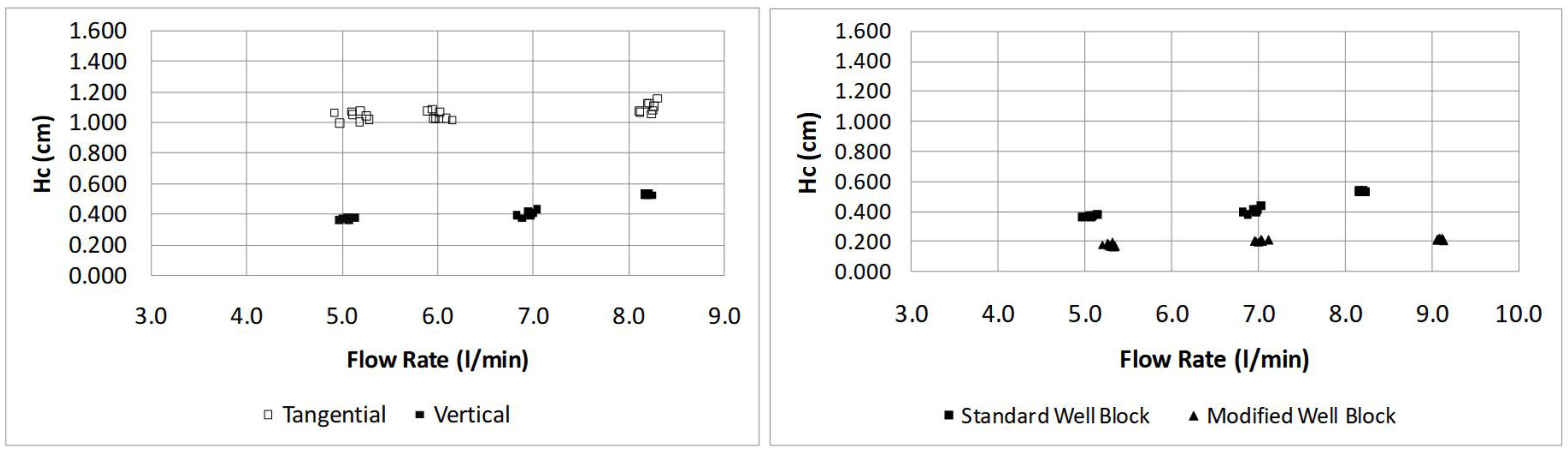

Figure 3. Left: $\mathrm{H}_{\mathrm{C}}$ values as a function of flow rates for a vertical filling and tangential filling - standard well block configuration. Right: Comparison between standard and modified well block - different flow rates; after 10 minutes of resting time.
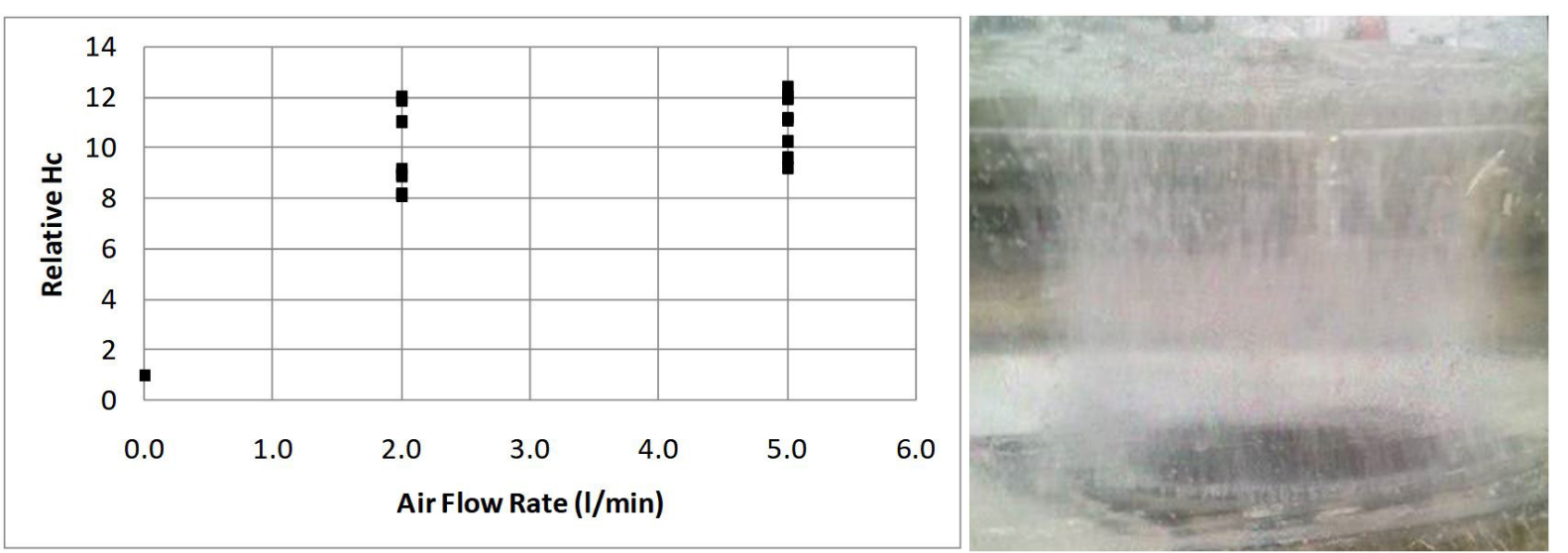

Figure 4. Relative $\mathrm{H}_{\mathrm{C}}$ against air flow rate on the modified well block system (left) for water flow rate of $8 \mathrm{I} / \mathrm{min}$. Photo of the physical simulation (right).

Table 3. F-Test for two populations (left) and T-Test for mean of two populations with equal variance (right)

\begin{tabular}{lccccc}
\hline \multicolumn{1}{c}{ F-Test } & Hc - Standard & Hc - Modified & T-Test & Hc - Standard & Hc - Modified \\
\hline Mean & 0.53 & 0.22 & Mean & 0.53 & 0.22 \\
Variance & $\mathrm{I} .99 \mathrm{E}-05$ & $3.22 \mathrm{E}-05$ & Variance & I.99E-05 & $3.22 \mathrm{E}-05$ \\
Observations & 8 & 8 & Observations & 8 & 8 \\
Gl & 7 & 7 & Difference of mean hypotesis & 0 & 14 \\
$\mathrm{~F}$ & 0.618 & & $\mathrm{gl}$ & 124.39 \\
$\mathrm{P}(\mathrm{F}<=\mathrm{f})$ one tailed & 0.270 & & Stat t & 2.14 \\
F critical one tailed & 0.264 & & t critical two tailed & \\
\hline
\end{tabular}




\section{I Numerical Model}

The critical value for vortex formation $\mathrm{Hc}$ as derived from the numerical model and from the physical modeling are in good agreement as it can be seen on Table 4. Hc has been used by Ribeiro [15] for partial validation purposes. The Figure 5 shows the phases distribution when the liquid level is just approaching $\mathrm{H}_{C}$. The blue color means water volume fraction $\left(\mathrm{V}_{\text {water }}\right)=0$ and red color means $\mathrm{V}_{\text {waterf }}=1$ or water volume fraction $=\mathrm{I}$. As it can be seen the $\mathrm{H}_{c}$ value is significantly smaller if the new well block design is adopted.
Also the mass flow rate curve at onset of drain sink formation is stepper in case of the modified well block (Figure 6). This behavior would be related to a smaller degree of second phase entrainment.

Table 4. Physical and numerical results

\begin{tabular}{ccc}
\hline Hc (Flow Rate $=8$. II/min) & $\begin{array}{c}\text { Physical } \\
\text { (cm) }\end{array}$ & $\begin{array}{c}\text { Numerical } \\
(\mathbf{c m})\end{array}$ \\
\hline Standard & 0.53 & 0.6 \\
Modified & 0.22 & 0.2 \\
\hline
\end{tabular}
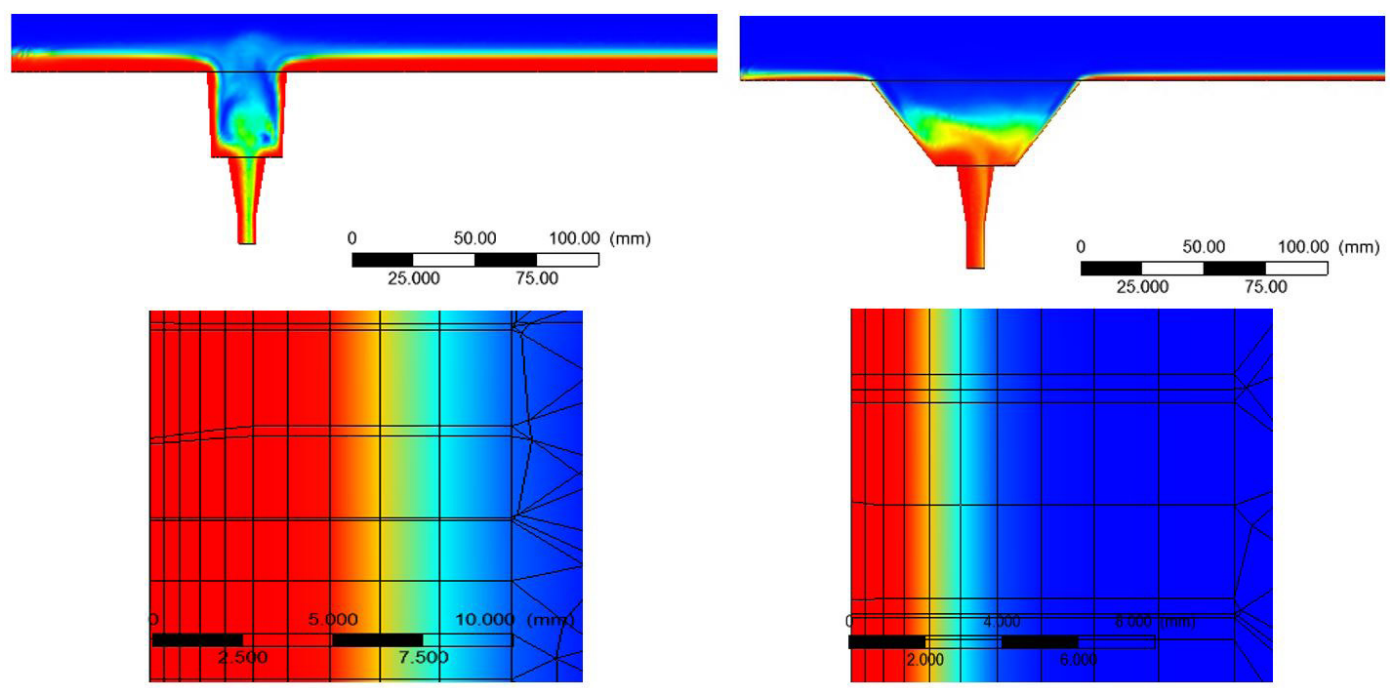

Fluid 1.Volume Fraction

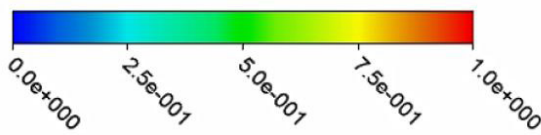

Figure 5. On the left (standard system). On the right (modified system): liquid level at onset of drain sink formation. In the middle bellow the legend.

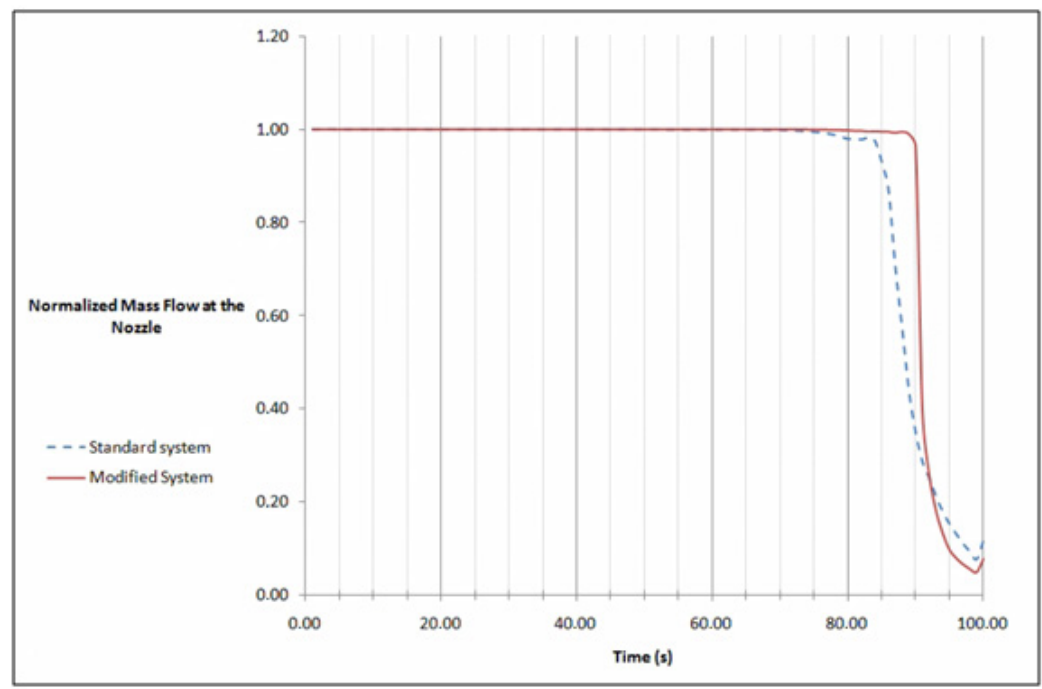

Figure 6. Mass flow rate versus teeming time. 

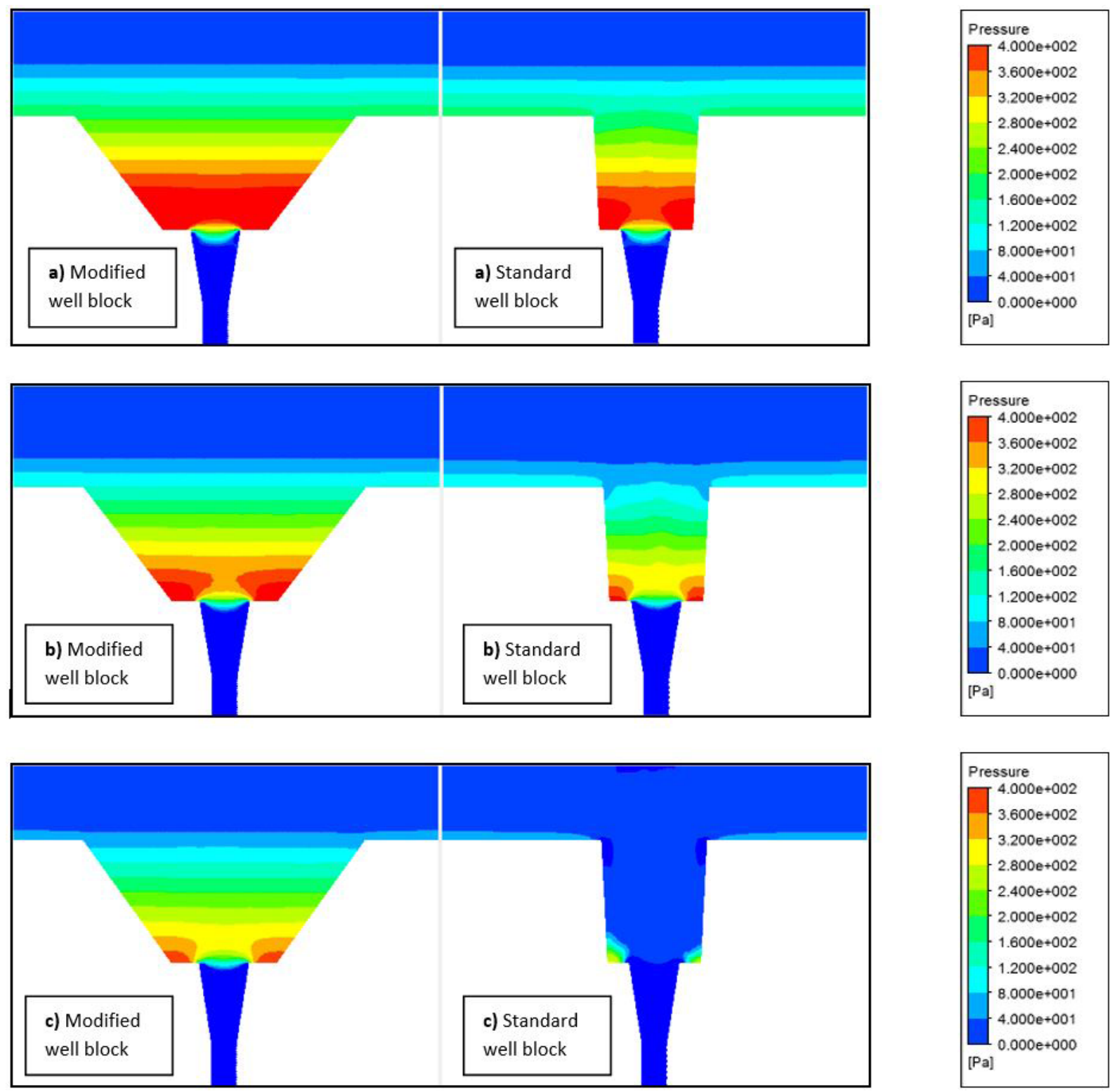

Figure 7. Pressure distribution for three water level condition: (a) $17 \mathrm{~mm}$ (b) $10 \mathrm{~mm}$ and (c) $5 \mathrm{~mm}$.

In order to explain these differences a pressure distribution towards the well block for three different water level was simulated: $17 \mathrm{~mm}, 10 \mathrm{~mm}$ and $5 \mathrm{~mm}$ from the bottom of the ladle. It is quite clear that as the water level decreases the new well block design can provide a higher pressure condition at the center of the nozzle bore avoiding for a longer time that the axial pressure collapse allowing second phase entrapment (Figure 7).

\section{CONCLUSION}

With all presented it can be concluded:

- The new well block configuration leads to, for all flow rates, a statistically proved reduction on the
$H_{c}$ value. It could represent almost $50 \%$ of metallic lost savings;

- Air injection was not effective in reducing the $\mathrm{H}_{C}$ value. However no air entrapment was observed showing potential as far as inclusion removal;

- The mathematical model showed very good agreement with the physical model, being a very important tool for a faster and costumer made developing solution. 


\section{REFERENCES}

I Hammerschmid P. Vortex formation during drainage of metallurgical vessels. Ironmaking \& Steelmaking. 1984; I I (6):332-339.

2 Sankaranarayanan R, Guthrie R. Slag entrainment through a "funnel" vortex during ladle teeming. In: The Metallurgical Society of the Canadian Institute of Mining and Metallurgy. Steelmaking Conference; 1992; Ontario, Canadá. Cidade: editora. p. 655-664.

3 Davila O, Morales R. Mathematical simulation of fluid dynamics during steel draining operations from a ladle. Metallurgical and Materials Transactions. 2006;37B:7I-87.

4 Kato H. Quality improvement of unstable zone by ladle slag detection system for continuous casting. ISIJ International. 1992;5:54-59.

5 Zhang Q. Numerical simulation and manifold learning for the vibration of molten steel draining from a ladle. Journal of Vibroengineering. 2013;15:549-556.

6 Santos S. Estudo do mecanismo de formação de vórtice durante a etapa de vazamento do aço da panela para o distribuidor do lingotamento contínuo da CST através da modelagem física [Dissertação de mestrado]. Ouro Preto: Universidade Federal de Ouro Preto; 2006.

7 Kojola N. Prediction and disarming of drain sink formation during unsteady-state bottom teeming. ISIJ International. 2009;49:I-9.

8 Mazzaferro G. Experimental and numerical analysis of ladle teeming process. Ironmaking \& Steelmaking. 2004;3I (6):503-508.

9 Sankaranarayanan R. Ironmaking \& Steelmaking. 2002; 147:234-240.

10 Lange M. Clean steel block - new developments towards clean steel. La Revue de Métallurgie-CIT. 2003;6:577-582.

II Morales O, Davila M. Physical and mathematical models of vortex flows during the last stages of steel draining operations from a ladle. ISIJ International. 20|3;5:782-79|.

$12 \mathrm{Li} \mathrm{W}$. Mechanism analysis of free-surface vortex formation during steel teeming. ISIJ International. 20I4;54:I5921600.

13 ANSYS. Turbulence and wall function theory [help system CD-ROM]. 2015.

14 ANSYS. Multiphase flow theory [help system CD-ROM]. 2015.

I5 Ribeiro B. Analise numérica e experimental do processo de vazamento de aço líquido da panela de aço para distribuidores no processo de lingotamento contínuo [Dissertação de mestrado]. Belo Horizonte: Universidade Federal de Minas Gerais; 2014.

Received: 4 Apr. 2018

Accepted: 10 Oct. 2018 